\title{
TAKING AND THE DISRUPTION OF COOPERATION ${ }^{1}$ \\ David R. Schmitt and Gerald Marwell
}

\author{
UNIVERSITY OF WASHINGTON AND UNIVERSITY OF WISCONSIN
}

\begin{abstract}
Subjects could either cooperate or respond on a lower-paying individual task. In Exp. I and II, either subject could make a response that took $\$ 1.00$ of the other's earnings whenever subjects chose to cooperate. The two experiments differed as to whether taking responses were effective continuously or intermittently. Both experiments showed that the opportu. nity to take disrupted cooperative behavior. Experiment III indicated that if taking was possible regardless of whether the subjects cooperated or responded on the individual task, subjects either cooperated or terminated the experiment.
\end{abstract}

Several experiments have shown that human cooperative responses, like individual behavior, are controlled by their relation to reinforcement (e.g., Azrin and Lindsley, 1956; Cohen, 1962; Lindsley, 1966; Mithaug and Burgess, 1968). Marwell, Schmitt, and Shotola (in press) have explored the effects of another reinforcement variable on rate of cooperative behavior. Cooperation yielded greater reinforcement than non-cooperation but also entailed the risk that either subject could take a specified amount of the other's earnings. If the alternative of taking was available, most subjects first took and then opted not to cooperate by engaging in an individual task yielding less reinforcement.

The three experiments reported here specify further some of the conditions under which the opportunity to take from a partner disrupts ongoing cooperative behavior. The first two experiments compared the effects of different schedules under which the taking response was effective. In Exp. I, the response could occur whenever both subjects chose to cooperate. In Exp. II, the response could occur intermittently. Experiment III investigated the effect of taking when this response was possible during either cooperative or individual activity.

${ }^{1}$ This research was supported by a grant from the National Science Foundation (GS-1695). Experiment I was part of a larger study in which Dr. Robert Shotola collaborated. Reprints may be obtained from David $\mathbf{R}$. Schmitt, Department of Sociology, University of Washington, Seattle, Washington 98105; or from Gerald Marwell, Department of Sociology, University of Wisconsin, Madison, Wisconsin 53706.

\section{EXPERIMENT I}

METHOD

\section{Subjects}

Four pairs of college students (three female and one male) volunteered to work as paid participants.

\section{Apparatus}

Each of the subject rooms contained a tablemounted panel 9 by 18 in. $(22.9$ by $45.7 \mathrm{~cm})$ with a plunger (Lindsley knob), a switch for choosing to work on a cooperative or an individual task, a button for taking money from the partner, stimulus lights, and two add-subtract counters. All functions were labelled. A diagram of the panel is shown in Fig. 1. The white light in the lower right illuminated for $0.1 \mathrm{sec}$ or for $3 \mathrm{sec}$ whenever the other subject made a response. The green lights next to the counters flashed for every reinforcement count registered. Each count was worth 0.1 cent. Counters showed accumulated earnings for the current 2-hr session only. For all sessions after the first, both subjects' previous totals were written on a blackboard on the wall directly behind the panel. A closed-circuit television receiver to the left of the panel showed the amount of money available to each subject for work on each of the tasks.

\section{Procedure}

Subjects reported to separate waiting rooms in the laboratory area and were escorted indi- 


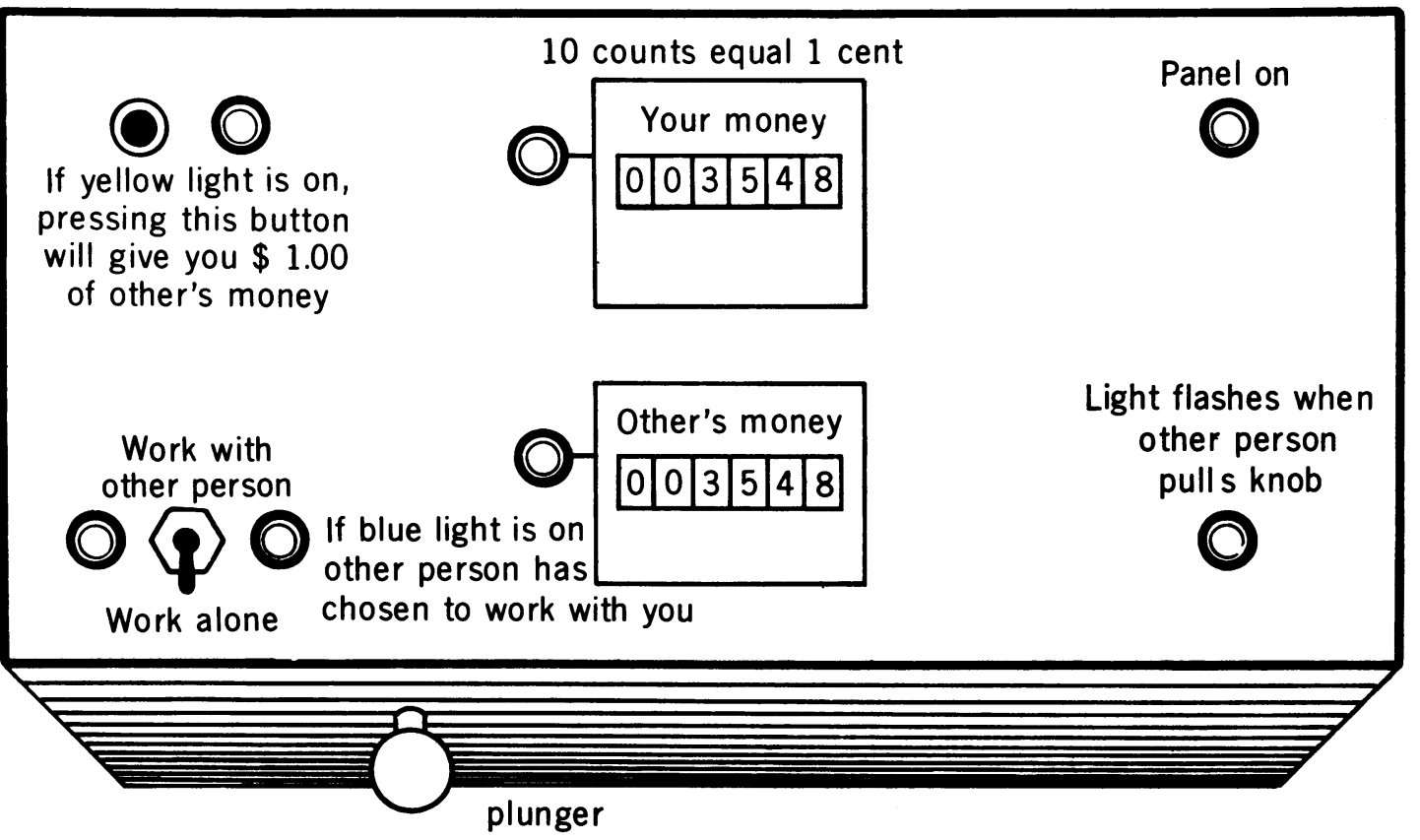

Fig. 1. Diagram of subject panel.

Table 1

Conditions Defining Training and Baseline Segments

\begin{tabular}{|c|c|c|c|}
\hline \multirow[b]{2}{*}{ Segment } & \multicolumn{2}{|c|}{ Reinforcers } & \multirow[b]{2}{*}{ Length of Segment } \\
\hline & $\begin{array}{l}\text { Cooperation } \\
\text { (Each Subject) }\end{array}$ & Individual & \\
\hline \multicolumn{4}{|l|}{ SESSION 1} \\
\hline $\begin{array}{l}1 \text { training (cooperation only) } \\
2 \text { training (In this and all sub- } \\
\text { sequent segments cooperation } \\
\text { or individual responding was }\end{array}$ & 0.64 & none & 335 cooperative responses \\
\hline $\begin{array}{l}\text { possible.) } \\
3 \text { training } \\
4 \text { baseline-no taking }\end{array}$ & $\begin{array}{l}0.1 \phi \\
0.6 \phi \\
0.3 \phi\end{array}$ & $\begin{array}{l}0.6 \phi \\
0.1 \phi \\
0.2 \phi\end{array}$ & $\begin{array}{l}135 \text { individual responses } \\
135 \text { cooperative responses } \\
15 \mathrm{~min}\end{array}$ \\
\hline \multicolumn{4}{|l|}{ SEssion 2} \\
\hline $\begin{array}{l}5 \text { baseline-no taking } \\
6 \text { taking } \\
7 \text { baseline-no taking }\end{array}$ & $\begin{array}{l}0.3 \phi \\
0.3 \phi \\
0.3 \phi\end{array}$ & $\begin{array}{l}0.2 \phi \\
0.2 \phi \\
0.2 \phi\end{array}$ & $\begin{array}{l}30 \mathrm{~min} \\
75 \mathrm{~min} \\
15 \mathrm{~min}\end{array}$ \\
\hline \multicolumn{4}{|l|}{ SESSION 3} \\
\hline $\begin{array}{l}8 \text { baseline-no taking } \\
9 \text { taking } \\
10 \text { baseline-no taking }\end{array}$ & $\begin{array}{l}0.3 \phi \\
0.3 \phi \\
0.3 \phi\end{array}$ & $\begin{array}{l}0.2 \phi \\
0.2 \phi \\
0.2 \phi\end{array}$ & $\begin{array}{l}30 \mathrm{~min} \\
60 \mathrm{~min} \\
15 \mathrm{~min}\end{array}$ \\
\hline \multicolumn{4}{|l|}{ SESSION 4} \\
\hline $\begin{array}{l}11 \text { baseline-no taking } \\
12 \text { taking }\end{array}$ & $\begin{array}{l}0.3 \phi \\
0.3 \phi\end{array}$ & $\begin{array}{l}0.2 \phi \\
0.2 \phi\end{array}$ & $\begin{array}{l}30 \mathrm{~min} \\
90 \mathrm{~min}\end{array}$ \\
\hline \multicolumn{4}{|l|}{ SESSION 5} \\
\hline $\begin{array}{l}13 \text { baseline-no taking } \\
14 \text { taking } \\
15 \text { baseline-no taking }\end{array}$ & $\begin{array}{l}0.3 \phi \\
0.3 \phi \\
0.3 \phi\end{array}$ & $\begin{array}{l}0.2 \phi \\
0.2 \phi \\
0.2 \phi\end{array}$ & $\begin{array}{l}30 \mathrm{~min} \\
60 \mathrm{~min} \\
15 \mathrm{~min}\end{array}$ \\
\hline
\end{tabular}


vidually to their experimental rooms. A subject did not meet his partner at any time during the experiment.

Before the first segment of the training session (see Table 1) subjects were instructed in the operation of the cooperative task. Only coordinated responses were reinforced. Either subject could pull first, thus illuminating the white response light on the other's panel for 3 sec. Reinforcement (a counter advance of six counts) occurred whenever the second subject pulled his plunger in the 0.5 -sec period after the response light went out; this response illuminated the response light on the other subject's panel for $0.1 \mathrm{sec}$. If the second subject pulled the knob before or more than $0.5 \mathrm{sec}$ after the response light went off there was no counter advance. Instead, the next response by either subject reinitiated the other's response light for $3 \mathrm{sec}$. Consecutive pulls by a subject responding first also initiated the other's response light for $3 \mathrm{sec}$. Each reinforcement was followed by a 2-sec period during which cooperative responses were not reinforced. The red panel light was turned off during this period. (See Schmitt and Marwell, 1968, for a more complete discussion of the characteristics of the task.)

Before Segment 2, subjects were instructed in the operation of the individual task and the task selection switch. On the individual task, each pull of the plunger advanced the counter and illuminated the response light on the other subject's panel for $0.1 \mathrm{sec}$. To equate the frequency of counter advances in time under the two conditions, each individual response was followed by a 5-sec period in which the red panel light was turned off and responses were not reinforced. The cooperative response with its initial 3-sec interval and 2-sec timeout also required a minimum of $5 \mathrm{sec}$ to be completed.

Each subject could choose to work on either the individual or cooperative task by operating the toggle switch on his panel. The cooperative task could be performed only if both subjects chose to work together. If either or both chose to work alone, the individual task operated for both subjects. A blue light on each subject's panel was illuminated whenever his partner switched to "work with other person". Thus, each subject was always informed of his partner's task choice.

In Segment 2, each subject received 0.6 cent for the individual task and 0.1 cent for cooper- ation. In Segment 3, these reinforcer magnitudes were reversed.

In the final $15 \mathrm{~min}$ of the training session (Segment 4) subjects worked under the baseline condition. Subjects received 0.3 cent for cooperating and 0.2 cent for working individually. Subjects working for 0.2 cent on the individual task could earn approximately $\$ 1.25$ per hour, an amount previously found sufficient to maintain participation in the experiment.

Session 2 began with 30 min of the baseline condition (Segment 5) to determine whether steady-state cooperation would be maintained by the 0.1-cent difference (steady-state cooperation was defined as at least $80 \%$ of a baseline segment on the cooperative task). At the beginning of Segment 6, a cover was removed from the take button and the following instructions were given to the subjects:

Each of you now has a button which you can press to take money from the other person. Each time you press the button you take one dollar from the other person and give one dollar to yourself. If the other person has less than one dollar, pressing the button will take away almost all of his money, down to about one cent.

Each subject pressed the button and observed the resulting transfer. Approximately $1 \mathrm{~min}$ was required to transfer $\$ 1.00$ after the take button was pressed. During this time the panel light went off, a buzzer sounded continuously, and neither cooperation, individual responses, nor taking was reinforced.

Subjects were then instructed in the function of the task-selection switch in taking:

Both of you turn your switches to "work alone". As you see, the amber light shows that the "take money" button is now off. The button is off whenever either one or both of you switches to "work alone". It is on only when you both switch to "work with the other person".

The task-selection switch remained operative during the transfer of money. Thus, if either subject switched to the individual task, the take button would be inoperative when the transfer was completed.

A 75-min take segment followed the instructions. In all but Session 4 this segment was followed by a 15-min baseline segment in 
which the take buttons were inoperative and covered. The take segment was $90 \mathrm{~min}$ in Session 4 and $60 \mathrm{~min}$ in Sessions 3 and 5 . At the beginning of the third and all subsequent sessions, a 30-min baseline segment preceded the take segment. As in Session 2, this segment permitted each of the subjects to earn approximately $\$ 1.00$ before any opportunity to take, and in addition determined the reversibility of any effects.

\section{RESULTS}

Figure 2 shows the cooperative and individual response rates for each pair during total time spent under baseline and taking conditions in Sessions 2 through 5. With no opportunity to take (baseline), pairs spent almost all of their time cooperating. Individual responding was limited to occasional single responses at the beginning of a segment and a number of responses by one pair during the final 15-min baseline segment in Session 5. With taking possible, all four pairs of subjects evidenced substantial disruption of cooperation. Three of the pairs stopped cooperating almost entirely and the subjects worked individually.

In the three non-cooperative pairs, taking was confined to Sessions 2 and 3. Typically, a switch to cooperation by one subject was followed by a nearly simultaneous switch to cooperation with taking by the other, who then

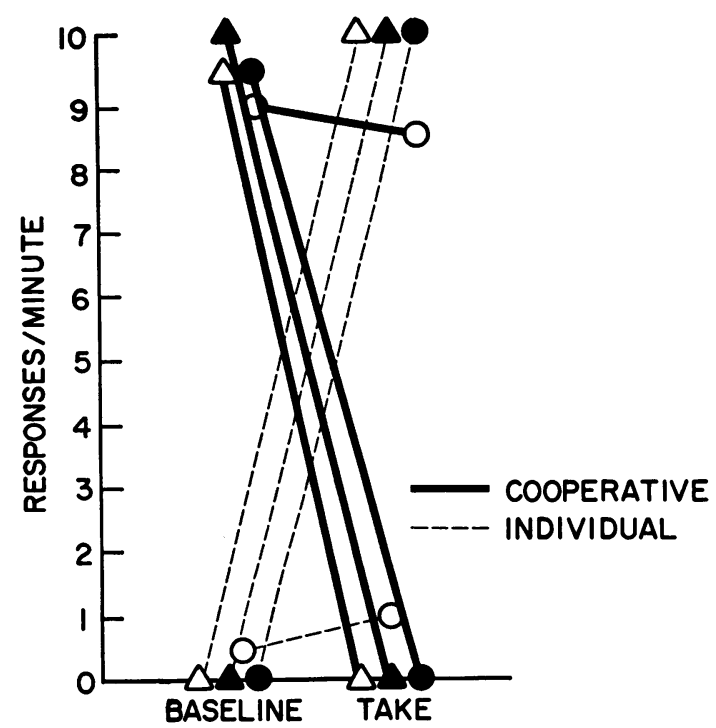

Fig. 2. Cooperative and individual response rates during total time under baseline and take conditions. switched immediately back to the individual task. In two of these pairs, only one subject took: 15 times in one pair and three times in the other. In the third pair, one of the subjects took once in Session 2. The pair began Session 3 by cooperating, but after 13 cooperative responses, the subject who had lost in Session 2 took. The pair did not cooperate for the remainder of the take segments. In these three pairs, cooperation resumed whenever baseline conditions were reinstituted and the opportunity to take was absent.

The fourth pair cooperated for substantial periods during each session. Both subjects took four times in Session 2 but cooperated totally throughout Sessions 3 and 4. However, during the final $8 \mathrm{~min}$ of Session 5 , one subject again took and chose to work individually. Atypically, cooperation did not reappear during the subsequent baseline period.

\section{EXPERIMENT II}

Experiment I showed that the continuous availability of a taking response disrupted cooperation. Experiment II was designed to determine if the intermittent availability of this response would produce similar results. In this experiment, taking was possible at irregular intervals during the experimental segments.

\section{METHOD}

\section{Subjects and Procedure}

Five pairs of female college students worked under the same procedures as used in Exp. I with the following exceptions:

1. Reinforcer magnitudes in the baseline and initial take segments were 0.4 cent for each cooperative response and 0.3 cent for each individual response (compared with 0.3 cent and 0.2 cent respectively in Exp. I). Experiment II was conducted several months after Exp. I and the increases were instituted to continue to make the minimum amounts subjects could earn comparable to the increasing scale of other university work. For pairs $C-H$ and $T-K$ it was necessary to increase the reinforcer for cooperation to 0.5 cent during the baseline segment in Session 2 to produce almost total cooperation. When these pairs proceeded to the take segment, the larger reinforcer was maintained.

2. In each session, a 30-min baseline pre- 
ceded a 90-min take segment, and sessions ended after the take segment.

3. During the take segments in Sessions 2 and 3, the opportunity to take was scheduled intermittently rather than continuously. Twominute periods with taking possible were scheduled at irregular or variable times that averaged $30 \mathrm{~min}$ (VT 30 -min schedule). Three 2-min periods occurred during the 90 -min segment. The take button during the 2-min periods was operative (indicated by the amber light next to the button) only if both subjects had switched to the cooperative task. At other times, a switch to cooperation did not make taking possible. Thus, for subjects who cooperated, the amber light periodically flashed on without warning, indicating that taking was now possible. If subjects did not cooperate, no signal indicated the occurrence of the take periods.

Subsequent sessions for each pair depended upon the stability of the pair's previous behavior, determined by inspecting the cumulative records. If cooperation did not develop, the magnitude of the reinforcer for cooperation was increased to 0.9 cent. If a stable pattern of partial or total cooperation resulted under the VT 30-min schedule, the frequency of 2-min take periods was increased to an average of one every $5 \mathrm{~min}$ (VT 5 -min). Finally, for pairs that cooperated under the VT 5-min schedule, taking was made possible continuously during the periods of cooperation (as in Exp. I).

\section{Results}

As Fig. 3 shows, the VT 30-min schedule, with taking possible less than $7 \%$ of the time, resulted in little or no cooperation for three of the five pairs when they received 0.4 or 0.5 cent for cooperation. Two of these pairs, $L-G$ and $L-S$, never cooperated or took during two sessions. The third pair, $C-H$, cooperated during the first half of Session 2 before one subject took. The pair then worked individually for the remainder of Session 2 and all of Session 3. The final two pairs, $T-K$ and $H-L$, both cooperated often and took whenever possible. Overall rates of cooperation, however, were lower than in the baseline periods. Pair $T-K$ worked three and $H$-L four sessions under the VT 30-min schedule.

When the VT 5-min schedule was intro- duced for the two cooperating pairs, $T-K$ continued to cooperate and take during the first $30 \mathrm{~min}$ of two sessions. However, for the remainder of these two sessions and during an entire third session, the pair worked individually. Pair $H-L$ continued to cooperate and take whenever possible during a single session. In this pair's final session, taking was possible continuously. Under this condition, both cooperation and taking ceased.

In two of the three pairs totally disrupted by the VT 30 -min schedule, increasing the reinforcer for cooperation from 0.4 or 0.5 cent to 0.9 cent substantially increased the rate of cooperation. For pair $L-S$, steady-state cooperation, broken by periods of taking, emerged after two sessions. Pair $C-H$ also cooperated frequently, although both subjects switched repeatedly from one task to the other and took several times during the two sessions. The third pair, $L-G$, continued to work totally on the individual task for two sessions. One or the other of the subjects occasionally switched to cooperation, but if her partner did likewise, the other would return immediately to the individual task.

When the VT 5-min schedule was introduced for the two newly cooperating pairs, $L-S$ continued to cooperate and no taking occurred. The pair remained totally cooperative during a final session when taking was possible continuously, and also when the reinforcer was reduced to 0.4 cent during the last $30 \mathrm{~min}$ of the session. For pair $C-H$, however, the VT 5-min schedule increased taking and individual responding by the end of the first session. During a second session, the pair worked solely on the individual task.

A potentially important constant in Exp. II was the 2-min period during which the opportunity to take was present when the pair was cooperating. This time period was sufficient to permit more than one take by the subjects. In most of the 2-min periods in which subjects took, more than one take occurred. Unlike Exp. I, subjects who took did not routinely switch immediately to the individual task. As a consequence, retaliatory taking often occurred. Thus, the 2-min take periods frequently ended with no net transfer of money. The failure of either subject to profit, however, did not appear to facilitate future cooperation or reduce taking, since cooperation was equally likely after two takes by a single subject. In ad- 


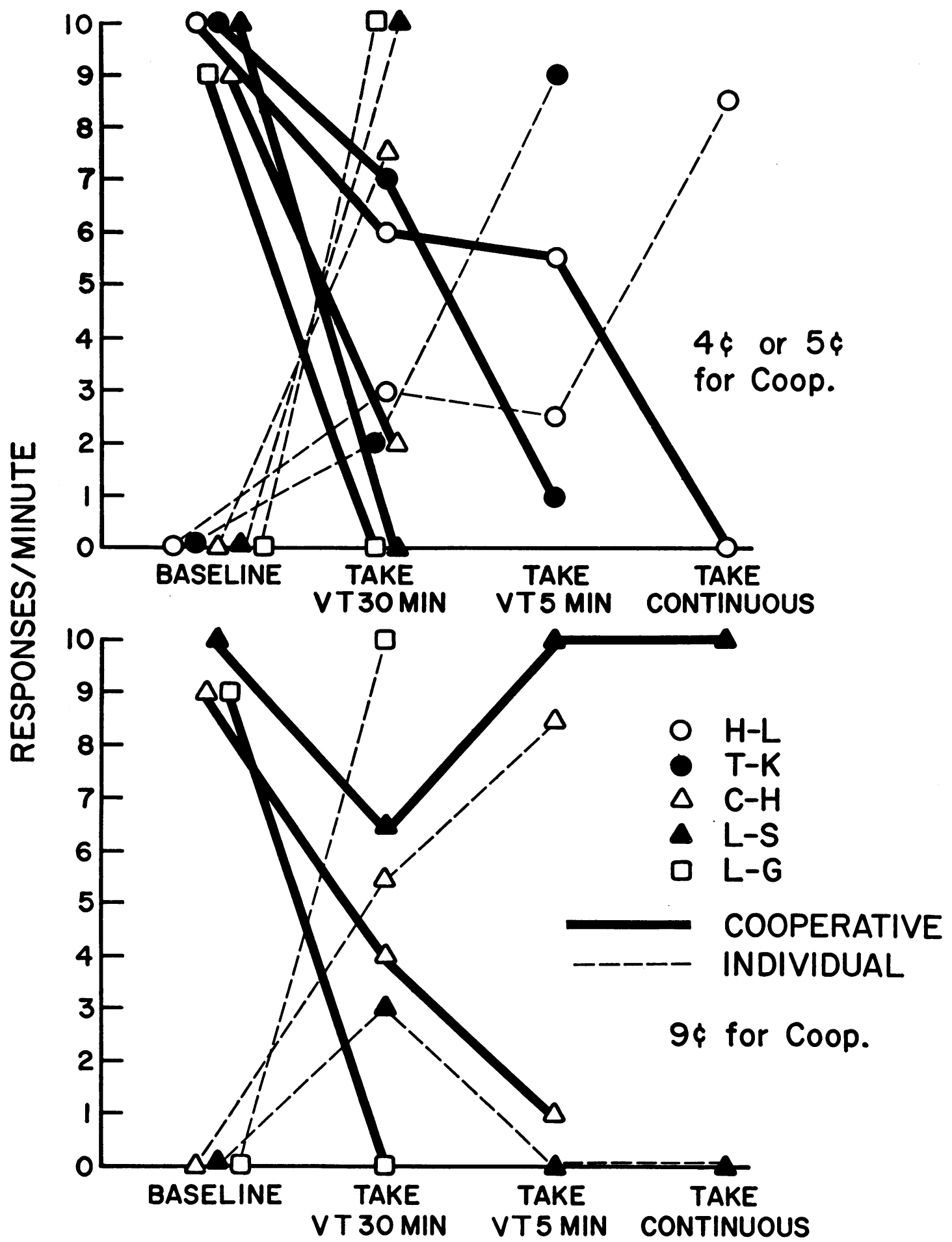

Fig. 3. Cooperative and individual response rates during total time under the various schedules. The upper half of the figure shows the response rates under the initial 0.4 - or 0.5 -cent reinforcement magnitudes for cooperation. The lower half shows the response rates of the three groups who worked under the 0.9-cent reinforcement magnitude for cooperation after little cooperation under the initial magnitudes. 
dition, continuous cooperation never emerged in the two groups in which takes by both subjects appeared most frequently, $T-K$ and $H-L$. The simplest explanation of the multiple takes is that subjects were trying to maximize the number of times they took during the short times available.

\section{EXPERIMENT III}

Experiments I and II showed that over time, subjects typically avoided the higher-paying cooperative task when taking was possible. Experiment III determined how cooperation was affected by the opportunity to take, regardless of task choice. A similar condition, run for a short period of time in the earlier study (Marwell et al., in press) produced some increase in cooperation.

\section{METHOD}

\section{Subjects and Procedure}

Six pairs of college students (five female and one male) worked under procedures that were the same as those for Exp. I, except that during the first three take segments, taking was possible continuously regardless of task choice. If stable cooperation occurred, the conditions were changed so that taking was possible only when subjects cooperated (as in Exp. I and II). Finally, the earlier continuous condition was repeated. The reinforcement magnitudes were those used in Exp. II.

\section{RESULTS}

As Fig. 4 shows, the continuous opportunity to take eventually resulted in cooperation in four of the six pairs. The cooperating pairs differed mainly in the time required before cooperation emerged. Cooperation began early in Session 2 for pairs $W-S$ and $P-C$, in Session 3 for pair $E-H$, and in Session 4 for pair $L-P$. Taking occurred in each of these pairs and was nearly continuous before cooperation. During this period, few task responses of either kind were made. When cooperation began, taking ceased for three of the four pairs. The three continued cooperating during the final session when taking was possible only during periods of cooperation.

The fourth pair, $P-C$, began cooperating early in Session 2 and continued thereafter ex-

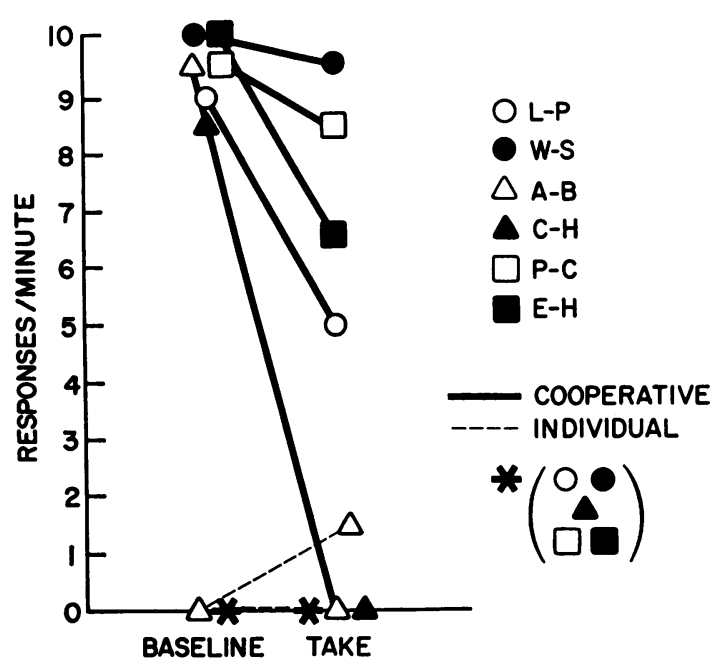

Fig. 4. Cooperative and individual response rates during total time under baseline and take conditions.

cept for several takes by both subjects at the ends of Sessions 3 and 4. When in Session 5 taking could occur only when subjects cooperated, the pair began by cooperating. However, following taking by both subjects, Subject $P$, who at that point had most of Subject $C$ 's money, began working individually. After approximately $30 \mathrm{~min}$, Subject $C$ walked out of the experiment and refused to come back for a previously scheduled sixth session.

The remaining two pairs also refused to continue in the experiment. Although both pairs were originally scheduled for six sessions, one subject in each group quit after Session 2. In both pairs, taking in Session 2 had been continuous. In one of the pairs, the subject who quit had earned slightly more than her partner, while in the other, her partner had taken most of the money.

\section{DISCUSSION}

The three experiments demonstrated that the opportunity to take generally disrupted or eliminated ongoing cooperative behavior. Disruption was greatest in Exp. I, when taking could occur whenever subjects cooperated. Cooperation was also disrupted in Exp. II where taking was possible only occasionally during periods of cooperation. For pairs that were largely cooperative when taking was possible infrequently, increased opportunity to take eliminated cooperation. Even under the high- 
est reinforcement magnitude for cooperation, where subjects could each earn over $\$ 5.00$ per hour, two of three pairs stopped cooperating when taking could occur frequently.

In Exp. I, with taking possible continuously during periods of cooperation, two pairs never made any cooperative responses and a third made very few. Therefore, cooperation was rarely or never reinforced in the presence of take opportunities, a factor that might account for its absence. In Exp. II, however, four pairs ultimately. cooperated for substantial periods under the VT 30-min take schedule (two after the reinforcement for cooperation had been markedly increased). Yet in only one did cooperation continue when opportunities to take were more frequent or continuous. Thus, the results further emphasize the dependence of cooperation on the frequency with which taking is available regardless of the reinforcement received during periods of cooperation.

In Exp. III, with taking possible regardless of task choice, the disruption of cooperation was temporary. However, taking continued or even increased before subjects began cooperating. No pair was without some taking and in two of the pairs, taking was frequent and prolonged. The aversive character of taking under these conditions is suggested by the escape from the experiment itself by subjects in three pairs.

In conclusion, subjects in the present ex- periments typically made the response that provided the greatest and most immediate reinforcement, i.e., taking, despite the consequences to the partner and the subsequent loss of reinforcement when subjects ceased to cooperate. Since Marwell, et al. (in press) showed that subjects will not destroy $\$ 1.00$ of the other's money when it gives them nothing, the reinforcement for taking appears to be crucial.

\section{REFERENCES}

Azrin, N. H. and Lindsley, O. R. The reinforcement of cooperation between children. Journal of Abnormal and Social Psychology, 1956, 52, 100-102.

Cohen, D. J. Justin and his peers: an experimental analysis of a child's social world. Child Development, 1962, 33, 697-717.

Lindsley, O. R. Experimental analysis of cooperation and competition. In T. Verhave (Ed.), The experimental analysis of behavior. New York: AppletonCentury-Crofts, 1966. Pp. 470-501.

Marwell, G., Schmitt, D. R., and Shotola, R. Cooperation and interpersonal risk. Journal of Personality and Social Psychology (in press).

Mithaug, D. E. and Burgess, R. L. The effects of different reinforcement contingencies in the development of social cooperation. Journal of Experimental Child Psychology, 1968, 6, 402-426.

Schmitt, D. R. and Marwell, G. Stimulus control in the experimental study of cooperation. Journal of the Experimental Analysis of Behavior, 1968, 11, 571-574.

Received 1 June 1970. 